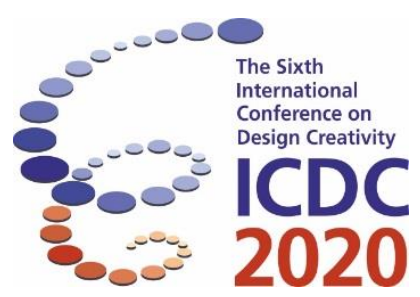

\title{
Retrospective and Prospective of the Study of Design Creativity: 80 Years into the Past and the Future
}

\author{
Ricardo Sosa ${ }^{1,2}$ \\ ${ }^{1}$ Art, Design \& Architecture, Monash University Melbourne, Australia \\ ${ }^{2}$ Design and Creative Technologies, AUT, Auckland, New Zealand
}

\begin{abstract}
Design creativity is a special type of imaginative capacity that plays an important, albeit still little understood, role in design activity. This paper returns to the primary sources to inform a critical review of the early studies of creative reasoning that have heavily influenced what we know and how we know it. It does this to inductively and reflectively formulate a prospective for the future study of design creativity that emphasizes a designerly outlook, facilitation skills, associative reasoning, the unearthing of assumptions, methodological awareness, types and stages of design ideas, design briefs, and purpose of ideation. A rethinking of the premises underlying the study of creative ideation has the potential to transform how we study, teach, and support the creative aspects of design practice in the twenty-first century and beyond.
\end{abstract}

Keywords: brainstorming, nominal groups, ideation, research methods, design practice

\section{Introduction}

In the last seven decades, research on creativity has made substantial contributions to our understanding of creative cognition (Dietrich, 2015), creativity methods (Treffinger, Isaksen et al., 2005), creativity self-perception (Karwowski and Kaufman, 2017), the learning of creativity (Scott, Leritz et al., 2004), creative teams and organizations (Mello and Rentsch, 2015), and the societal dimensions of creativity (Valsiner, Gillespie et al., 2015). These efforts have also revealed the great challenges for the study of creativity, and they form a complex and multi-dimensional image of the human capacity to imagine new futures and make them a reality -which we adopt as a general definition of creativity here. If one thing is clear from the last decades of creativity research is that it is a very difficult topic to study that defies definitions and transcends disciplinary conventions. Framing research questions and hypotheses, choosing appropriate research methods, setting up a study, analyzing and interpreting the results, and building theory are all phases that present singular problems for researchers. Design scholars have also paid attention to the more specific type of creativity that takes place in design activity. These studies range from laboratory studies of ideation (Gonçalves, Cardoso et al., 2013) to ethnographic studies of design creativity "in the wild" (Elsbach and Flynn, 2013; Yannou, 2013) and computational agent-based simulations to investigate first principles (Sosa and Gero, 2016). Those who study design creativity can learn substantially from the more general field of creativity research, but they must also identify what makes design creativity different from general creativity. By going back eight decades to the origins of what is arguably the best-known creativity method (brainstorming), we seek here to clarify and demystify some key ideas about the practice and the study of creativity. Our goal in doing this is to outline principles or guidelines that can inform studies of design creativity in the next eighty years. 
As a creativity method, group brainstorming is an octogenarian. While it has a bad name in some circles (McCaffrey, 2014; Chamorro-Premuzic, 2015), it is a technique widely used by practitioners (Shih, 2011; Shroyer, Lovins et al., 2018). The term brainstorming is colloquially used as "a group discussion of spontaneously arising ideas"1. Far from spontaneous and impromptu, brainstorming was conceived as a well-planned and structured technique for "idea finding" in the 1930s (Osborn, 1963). Since its inception, a primary recommendation was to conduct a "triple attack of individual-group-individual ideation" (Osborn, 1963) (p. 191) given that both ideation modes "can be just as productive" (Osborn, 1963) (p. 191). By the 1950s brainstorming had become "too popular too fast", resulting in it being misused and its efficacy exaggerated (Osborn, 1963) (p. 152). Around that time the first experimental studies concluding that "group participation when using brainstorming inhibits creative thinking" (Taylor, Berry et al., 1958) (p. 23) gained traction and influenced derivative but highly cited studies which claim that group ideation is inferior to individual ideation.

This paper revises the original sources to demystify and reframe brainstorming more rigorously as a structured ideation method widely used in design. It does this by returning to the primary sources to inform a critical review of the literature. Key ideas from these early sources, some of which have been largely ignored in the literature, are quoted here using lists for clarity and brevity. The paper then extracts guidelines for the future study of design creativity based on the perceived gaps between practice and research of design creativity. This work seeks to connect a retrospective analysis with a prospective synthesis by inductively and reflectively bridging what we know and how we know it with the open questions for future inquiry.

\section{Brainstorming turns eighty}

Early participants of "idea-producing conferences" named these sessions after their value to use "the brain to storm a problem" (Osborn, 1963) (p. 151). This technique has precedents in ancient traditional practices such as Prai-Barshana from India where generation and evaluation of ideas are deliberately separated (p.). Adequate brainstorms are informed by these key principles (Osborn, 1963):

- New ideas need "the most impartial scrutiny" because they can be "worthless or because we shall not know how to elicit their value" (p. 130). All new ideas need to be "sceptically entertained... for the thousandth idea may be the one that will change the world" (p. 130).

- The goal of a brainstorm is not to solve a problem, but to storm it, i.e., to produce "a checklist of ideas" that can "serve as leads" to be "subsequently evaluated and further processed" (p. 152).

- Group ideation is "relatively fruitless" unless participants "faithfully follow" these rules: rule out criticism; welcome "free-wheeling" (wild ideas); pursue quantity; seek to combine and improve ideas (p. 156). These have become known as the "four rules of brainstorming".

- Associative thinking is a key mechanism for "chain reactions" that produce "hitch-hikes" ideas (p. 273). This process of "re-processing ideas by means of modification and combination" can transform "mediocre ideas into sterling ideas" (p. 158).

To prepare creative sessions the following guidelines apply (Osborn, 1963):

- Adequately formulate the problem to be stormed. It needs to be specific, "simple rather than complex", and narrowed down to "a single target" (p. 173).

- Participants receive a background memo "at least two days in advance of the session" of "not more than one page in length" to let them "sleep on the problem thus allowing incubation to enhance the workings of association" (p. 198).

- The panel leader (facilitator) prepares their own list of ideas. When a session slows down or gets off track, they "can prime the joint flow of ideas by contributing some of their own" (p. 175).

- Leaders use their own ideas to prepare leads that they can suggest during a session "by way of classifications or categories" (p. 175). They also prepare "idea-spurring questions" to move a

\footnotetext{
${ }^{1}$ Oxford Dictionary definition: https://www.oed.com/view/Entry/304150
} 
session forward, such as "Put to Other Uses? Adapt? Magnify? Reverse? Combine?" (p. 176, 283).

To conduct creative sessions these recommendations are offered (Osborn, 1963):

- Participants only offer "one idea at a time" (p. 176). To achieve this, they are encouraged to "make notes of ideas they plan to offer when their turn comes" (p. 177).

- Turn-taking is expressly recommended to create opportunities for "hitch-hikes" by idea association, thus encouraging ideas that are "directly sparked by a previous idea" (p. 177).

- The leader monitors and incentivises the "spirit of a brainstorm session" for which both self and mutual encouragement are crucial (p. 157).

- A secretary captures all the ideas in ways that are "reportorially -not word for word" brainstorms can also be audio recorded (p. 157).

- In closing, participants are thanked and directed "to keep the problem on their minds until the next day when they will be asked for their afterthoughts" (p. 178). A list of all the ideas is sent to participants asking them to reply with new ideas formed after the session (p. 179).

The original source of brainstorming (Osborn, 1963) notes that besides generating a check-list of ideas (p. 157), brainstorms have five additional functions: they can be "tools for improving morale", to discover "what people think about problems", to "gain a better understanding of each other", to produce enjoyment (p. 189), and to supplement creative training (p. 163). Crucially, it indicates that "group brainstorming is recommended as a supplement to individual ideation" (pp. 142, 191, 203). When properly conducted, group brainstorming "can produce far more good ideas than a conventional conference -and in less time" (p. 152). To evaluate ideas from a brainstorm as initial leads for further processing, "the surest method of evaluation is to put our ideas to test. And the task of thinking up the best way to test is a creative challenge in itself" (p. 118).

As brainstorming became adopted by professionals during the 1950s, scholars directed their attention towards its empirical evaluation.

\subsection{The first decade of studies}

Fifteen papers with the word "brainstorming" were published between 1954 and $1963^{2}$, the first decade since the first edition of Osborn's book. Since then, nearly three-thousand papers have been published on this topic ${ }^{3}, 268$ in the last twelve months. The early studies of brainstorming were motivated by a range of goals including: a comparison of individual vs. group productivity (Taylor, Berry et al., 1958); the effects of brainstorming vs. "non-brainstorming" ideation instructions (Meadow, Parnes et al., 1959; Parnes and Meadow, 1959); the effects of group cohesiveness and types of task (Cohen, Whitmyre et al., 1960); the effects of the "rule out criticism" rule (Weisskopf-Joelson and Eliseo, 1961); the effect of time limits (Parnes, 1961); and the effects of homogeneous vs. heterogeneous groups and self, interaction, and task orientation (Gurman Jr, 1962).

Early researchers decomposed and narrowly studied some of the underlying mechanisms in isolation (Taylor, Berry et al., 1958; Meadow, Parnes et al., 1959; Parnes and Meadow, 1959; Cohen, Whitmyre et al., 1960; Parnes, 1961; Weisskopf-Joelson and Eliseo, 1961; Gurman Jr, 1962; Dunnette, Campbell et al., 1963). Most of these laboratory studies employed inexperienced students randomly assigned to experimental conditions. Researchers instructed them to generate ideas in response to a brief, assigned a time limit of five to fifteen minutes, and gave them a compensation. The ideas they produced were counted and judged by a panel for originality, uniqueness, appeal, feasibility, and/or value.

Early researchers reframed brainstorms as experimental procedures. In doing so, they failed to provide the brief to participants in advance thus preventing incubation; they also failed to include the strategically important role of facilitation and instead simply instructed participants to ideate and left them to their own devices. Lastly, the ideation tasks in these studies are fun but inconsequential toy exercises that are either too general and open-ended like the Tourist and Teacher problems, implausible imagination exercises like the Thumbs and People problems, or aimless divergent reasoning tasks like

\footnotetext{
${ }^{2}$ Web of Science report ALL FIELDS: ("brainstorming"); Timespan: 1954-1963

${ }^{3}$ Web of Science report TOPIC: ("brainstorming"); Timespan: 1964-2019.
} 
the Hanger and Broom problems (Taylor, Berry et al., 1958). Whilst seeking to rigorously study brainstorms, researchers removed essential practices that define this ideation method. For the last four decades, multiple researchers have noted that the study of brainstorming has failed to acknowledge and apply the guidelines to properly conduct it (Jablin and Seibold, 1978; Kalargiros, 2014). As a result, these studies ended up testing "quasi-brainstorming procedures" (Jablin and Seibold, 1978). Designed with questionable procedures, their findings and conclusions are problematic. This is particularly relevant for understanding how design creativity has been researched to date, and to inform future research in this area of design research.

Of the handful of early studies, (Taylor, Berry et al., 1958) became by far the most highly cited -with a current h-index $=54$ and 11,754 studies citing it ${ }^{4}$. That study first found that "on each of the three problems the mean total number of ideas produced by the twelve groups was considerably larger than the mean number produced by the forty-eight individuals, the difference being highly significant... on all three problems group performance is clearly superior to individual performance". Taylor, however, decided to incorporate the construct "nominal groups" from previous work on problem solving (Taylor and McNemar, 1955). Nominal groups are formed after the experiment is completed by adding the responses from the same number of individuals as the size of the real groups. The researchers then score the performance of nominal groups "by assuming that if any one in the group solved a particular problem, the group solved it" (p. 476) (Taylor and McNemar, 1955). With this setup to compare nominal vs. real groups brainstorming, the study found the performance of the real groups to be "markedly inferior to that of the nominal groups in terms of number of ideas produced". This finding was replicated a few years later (Dunnette, Campbell et al., 1963), and since then nominal groups spread like fire in creativity research (Lewis, Sadosky et al., 1975; Diehl and Stroebe, 1987; Paulus and Dzindolet, 1993; Nijstad and Stroebe, 2006). Some of the studies citing (Taylor, Berry et al., 1958) have captured more attention, in particular (Diehl and Stroebe, 1987) which could suggest that most studies using nominal groups may be unfamiliar with how this construct was first introduced in the primary source. Moreover, the term "nominal groups" appears in nearly $10 \%$ of the citations to (Osborn, 1963), according to Google Scholar statistics in November 2019. By comparison, only $0.1 \%$ include the term "triple attack" used by Osborn to recommend a threefold strategy of individual-group-individual ideation.

The validity of "nominal groups" can be challenged in general, and more specifically from a viewpoint of design creativity. First, comparing group vs. individual ideation contradicts the recommendation for "a triple attack" using individual-group-individual modalities. Second, measuring ideation on fluency and perceived quality of sketchy ideas ignores the other important functions of group ideation such as mutual understanding and training. Third, comparing the outcomes of real vs. nominal groups rises methodological predicaments including time allocation as noted by (Gurman Jr, 1962), since individuals working in groups of size $N$ have $1 / N$ of the time available to share their ideas compared to those working in isolation. Whilst "nominal groups" may be justified on the basis of number of people, their proponents ignore the significant difference in number of minutes between these conditions. Namely, the ideas generated by so-called nominal groups represent $N x t$ where $N$ is the number of brainstormers and $t$ is session time limit, whilst the ideas generated by real groups represent only $t$ time. A direct comparison between parallel and serial ideation is conceptually weak. Fourth, from a design viewpoint, the importance of collaborations for creative design is well documented by expert practitioners (Kocienda, 2018) as well as by ethnographic studies of professional designers (Elsbach and Flynn, 2013). As a result, a considerable number of creativity studies (those using nominal groups) tell us very little about brainstorming as used by practitioners.

Idea association in group brainstorming was originally presented as superior when the process is adequately facilitated. The rationale by Taylor for setting the time limit shows the critical disadvantage of not having adequate (or any) facilitation: "The time limit of twelve minutes for each problem was chosen, on the basis of considerable pretesting, as one which would permit group members to express all ideas occurring to them within the work period and at the same time not result in excessive periods of silence for individual subjects. In the actual experimental sessions, appreciable periods of silence appeared between responses near the end of the twelve minutes." (Taylor, Berry et al., 1958) (p. 46).

\footnotetext{
${ }^{4}$ Web of Science citation report for (Taylor, Berry et al. 1958).
} 
Precisely because ideation slows down, leaders are recommended to "prime the joint flow of ideas by contributing some of their own" and by suggesting "idea-spurring questions" (Osborn, 1963).

In summary, a good portion of the nearly fifty-thousand papers on creativity ${ }^{5}$ need to be taken with a pinch of salt due to their weak conceptual and methodological bases (Sutton and Hargadon, 1996; Isaksen and Gaulin, 2005). This is clear with studies of non-facilitated brainstorming using "nominal groups" which engage in a logical fallacy and create an illusory refutation of group ideation. Another significant weakness of creativity studies, which is of particular relevance for design scholars, is the overreliance on testing instruments focused on divergent thinking (Dietrich, 2015). Tests such as the Remote Associates and Alternate Uses measure verbal divergent reasoning and often use these psychometric instruments to conflate all creative abilities (Piffer, 2012). Unfortunately, many studies of creativity show a lack of creative facilitation experience by those studying ideation. The validity of studies that deviate in important ways from brainstorming procedures has been questioned, and studies that do not perform due diligence in implementing Osborn's recommendations are "a futile exercise" (Kalargiros, 2014). In the end, scholars who discredit brainstorming on these bases show a "lack of understanding, lack of adherence to critical procedural guidelines, [and a] parochial research agenda" (Kalargiros, 2014).

Whilst many studies of brainstorming lack validity, several phenomena associated with brainstorming have been studied over the last four decades, providing support for many (but not all, not yet) of the bases of this "idea-finding" method. Namely:

- Evidence generally supports idea fluency correlates with higher originality and novelty (Adánez, 2005). This "quantity breeds quality" dictum is explained in probabilistic terms: "the more ideas you think up, the more likely you are to arrive at the potentially best leads to solution" (Osborn, 1963) (p. 124). However, the central role of associative thinking in ideation suggests key combinatorial advantages. In a list of ideas, every new entry causes a significant growth of new connections, meanings, and paths for combining and modifying "leads to solution".

- The associative basis of creative thinking has been established and profusely studied (Mednick, 1962; Goldenberg and Wiley, 2019), giving support to the fourth rule of brainstorming and the observation that "most ideas are by way of combinations" (Osborn, 1963) (p. 282).

- The value of creative sessions beyond producing ideas -as noted by Osborn- has been demonstrated in ethnographic studies of ideation "in the wild" (Sutton and Hargadon, 1996).

- The longitudinal study of creative teams in the workplace has found evidence of two types of contributions from team members: giving and taking behaviours (Elsbach and Flynn, 2013). This can explain how ideation sessions produce leads to solutions that require further development and imaginative testing (Osborn, 1963).

- Studies of ideation where participants work on design problems rather than toy problems show a comparable performance between individuals and teams, even when not facilitated (Linsey, Clauss et al., 2011). Design ideas that are product of combinations and development of other ideas tend to be of superior quality (Linsey, Clauss et al., 2011), which supports the role of combinatorial processes to transform "mediocre ideas into sterling ideas" (p. 158).

- One of the few studies that compared established (worked together for 10 weeks) vs. nonestablished groups (only worked together once for the brainstorm session) confirms Osborn's claims about increased group efficiency (Levine, Heuett et al., 2017).

- Evidence confirms that "idea-spurring questions" can have positive effects in creative ideation (Moreno and Yang, 2014).

- Whilst many ideation studies rely on average values of fluency and metrics of idea quality, design researchers note that "extremes are what matter, not the average or the norm" (Girotra, Terwiesch et al., 2010) and draw attention to maximum values and variances. This supports Osborn's emphasis on the "thousandth idea" that will pay off (p. 130).

- Studies of ideation that address the effects of how design briefs or tasks are framed are rare, although their likely influence has been mentioned over the years (Meadow, Parnes et al., 1959;

\footnotetext{
${ }^{5}$ Web of Science report TOPIC: ("creativity"); Timespan: All years.
} 
Vasconcelos and Crilly, 2016). Osborn warned that failure to adequately frame a problem "can seriously mar the success of any brainstorm session" (Osborn, 1963) (p. 173).

\section{The future study of Design Creativity}

This section presents a prospective, partially informed by the examination of the last eighty years of brainstorming research, but also as an exercise of disciplined imagination for the type of theories that are needed to build knowledge on design creativity (Weick, 1989). In doing this, we recognise the conceptual and methodological gaps between the study of brainstorming and design creativity.

1. Emphasis on design creativity: Research on design creativity is needed to understand and to support design activity but also to bring a designerly voice to the mainstream study of general creativity. This requires that design scholars critically assess the relevance and applicability of the themes, methods, constructs, and definitions from mainstream creativity research for the advancement of design knowledge and practice. To illustrate with a simple example: whilst divergent thinking testing is accepted in areas of creative cognition as a means to separate "creative" and "non-creative" subjects, how many design researchers would defend a boundary between creative and non-creative designers, or that a psychometric test can predict the level of creativity of a designer in a project?

2. Emphasis on facilitation: Many design researchers study the effects of creativity methods and tools. To do this, they often simplify and "cleanse" ideation sessions obviating the role of facilitation. Meanwhile, practitioners and scholars of design creativity "in the wild" highlight contextual dimensions including psychological safety, mutual learning, trust, and facilitation. The study of design ideation sessions cannot be reduced to giving a tool or instructions to subjects and leave to their own devices to generate design concepts. When using brainstorming, the principles and rules used by practitioners should be accounted for in research studies: to train and prime participants in advance; to employ a skilled facilitator who has stormed the problem before; to decide what problem to storm and how it is framed and presented; to have a scribe; to justify the time allocated and the type of outputs that participants generate; and to follow up. Scholars of design creativity need to exercise due diligence.

3. Emphasis on association: Certain metrics may be less relevant in design ideation compared to more simple divergent thinking testing widely used in mainstream studies. Consider fluency: accomplished designers are recognised not by how many ideas they produce during a project, or how good those alternatives are on average. Instead, designers, or rather design teams, who generate ground-breaking solutions are celebrated by the impact of the solutions that they develop. What counts is the final outcome of a design project, and not their first half-baked sketchy concept produced in a short ideation session and vaguely interpreted by a panel of judges. This suggests that portraying creative designing as a process of sampling a design space until one great idea is found may be ill-informed; instead, creative designing may better be conceived as an extended combinatorial process where multiple combinations of fragmentary ideas are "sceptically entertained" until a great idea is formed (Sosa, 2019).

4. Emphasis on revealing assumptions: Scholars of design creativity do well to unearth and interrogate the assumptions inherited from mainstream studies of creativity. The research questions that guide the study of creativity are biased by the epistemological bases of the research domain: cognitive scientists aim to identify creative reasoning, neuroscientists look for brain regions that activate for creativity, and socioeconomic analysts identify a creative class using indicators like occupations and demographics. A key advantage (and simultaneously a challenge) for design scholars is that their research questions need not be prescribed by such disciplinary ways of knowing. In formulating designerly research questions about creativity, we are able to critically adopt, modify, or refute the assumptions and procedures of seminal works. For this, it is crucial to directly and carefully read the original sources.

5. Emphasis on methodology: Design creativity is a messy object of study (Law, 2004), calling for conceptual clarity and methodological resourcefulness in the framing and planning of our studies. Mixing methods to triangulate the study of design creativity seems likely to increase the validity and applicability of findings. To this end, design researchers benefit from cultivating 
collaborations to combine quantitative, qualitative, practice-based, computational, and other research methodologies. In contrast, studies of design creativity that merely rely on off-the-self applications of established methodologies from other disciplinary origins are likely to render less relevant results. When framing a study aimed at the effects of a method or tool, researchers do well in clearly establishing strategies and criteria for the falsification of their hypotheses.

6. Emphasis on design ideas: In mainstream creativity research ideas are defined as responses to tests or puzzle problems such as the Alternate Uses or the Remote Associates Tasks (Silvia, Winterstein et al., 2008). This treatment does not translate well in design studies where participants generate design concepts that have features of very different kinds: ergonomic, functional, aesthetic, cultural, etc. Terms such as ideas, concepts, designs, and solutions are interchangeably used across and within design studies denoting a treatment of concepts that lacks clarity, uniqueness, parsimony, and measurement properties. Studies of design creativity need to spell out a theoretically sound definition of design ideas and their genesis or formation process. Depending on the duration of the study, design ideas could be defined by their stage of development (Sosa, 2019).

7. Emphasis on design briefs: Design problems have characteristics that distinguish them from non-design problems (Goel and Pirolli, 1992). In mainstream creativity research, there are conceptual incentives to re-use standardized tests as mentioned before. At present we can only speculate how design briefs (also called tasks, problem statements and prompts) shape creative activity in design (Sosa Medina, Vasconcelos et al., 2018). Moreover, problem reframing is considered indicative of design creativity thus making it harder to limit our analysis to the solutions generated by participants without including how they may co-evolve the initial problem formulation (Dorst, 2015). Based on the original framing of brainstorming, a fruitful approach is to study participants as they work on storming a well-defined and narrow aspect of an open-ended and complex design problem.

8. Emphasis on ideation purpose: Design creativity sessions are often assumed to capture conceptual work that takes place in the "fuzzy front end" of the design process. However, practitioners use brainstorming throughout a project indicating that conceptual design takes place at various stages (Shroyer, Lovins et al., 2018). Hence, studies of design creativity can target a variety of purposes, from sessions where "fully-formed" ideas are sought to those aiming for early fragmentary ideas for further development. Depending on what type of ideas designers aim for, scholars should justify their data collection and analysis strategies and tools -and the claims derived from their findings need to be framed accordingly. Metrics of feasibility may only apply when design ideas are sufficiently developed and detailed, whilst metrics of persuasiveness and emotional response may be more suitable for early, sketchy, and tentative ideas.

\section{Discussion}

This paper went back to the original sources to critically examine the origins of brainstorming and of its systematic study. It then identified the fallacy behind "nominal groups" and reviewed evidence that does support many of the principles of group brainstorming. Recognising the distinctions between brainstorming and design creativity, the paper inductively and imaginatively framed an agenda for the future study of design creativity. The work presented here shows how critical it is to return to primary sources. Careful reading of classic studies is important with a critical view of the research questions, methods, and claims to avoid uninformed citations to (Taylor, Berry et al., 1958) to claim that: "There is considerable evidence that group brainstorming is less productive than individual brainstorming" (Kohn and Smith, 2011) (p. 359) -which is the opposite of what (Taylor, Berry et al., 1958) found.

Designers, design scholars, and design educators, can draw a few lessons from this retrospective and prospective work -despite its current limitations. Numerous misconceptions of creativity (Dietrich, 2015) are based on research that follows "academic rigour" but ignores the rigour of design practice. Moving forward, design research needs to acknowledge the double challenge of being scientifically and designerly relevant (Yee, 2017; Crilly, 2019). Advancing the knowledge, the methods and the tools for design creativity is urgently needed to address the crises of the twenty-first century and to imagine 
desirable futures. History shows that the best intended innovations have often had disastrous consequences in the long run, which underlines the strategic importance for the systematic study of creativity in general, and of design creativity in particular. The ways in which designers were educated in the twentieth century and the tools built for their practice were only marginally grounded (if at all) on valid and realiable evidence. A rethinking of the premises underlying the study of design creativity has the potential to transform how we study, teach, and support the creative aspects of design practice in the twenty-first century including the development of future technologies to support and extend human designers.

\section{References}

Adánez, A. M. (2005). "Does quantity generate quality? Testing the fundamental principle of brainstorming." The Spanish journal of psychology 8(2): 215-220.

Chamorro-Premuzic, T. (2015). Why Group Brainstorming Is a Waste of Time. Harvard Business Review. Cambridge, Harvard Business Publishing.

Cohen, D., J. W. Whitmyre and W. H. Funk (1960). "Effect of group cohesiveness and training upon creative thinking." Journal of Applied Psychology 44(5): 319.

Crilly, N. (2019). "Methodological diversity and theoretical integration: Research in design fixation as an example of fixation in research design?" Design Studies 65: 78-106.

Diehl, M. and W. Stroebe (1987). "Productivity loss in brainstorming groups: Toward the solution of a riddle." Journal of personality and social psychology 53(3): 497.

Dietrich, A. (2015). How Creativity Happens in the Brain, Springer.

Dorst, K. (2015). "Frame Creation and Design in the Expanded Field." She Ji: The Journal of Design, Economics, and Innovation 1(1): 22-33.

Dunnette, M. D., J. Campbell and K. Jaastad (1963). "The effect of group participation on brainstorming effectiveness for 2 industrial samples." Journal of applied psychology 47(1): 30.

Elsbach, K. D. and F. J. Flynn (2013). "Creative Collaboration and the Self-Concept: A Study of Toy Designers." Journal of Management Studies 50(4): 515-544.

Girotra, K., C. Terwiesch and K. T. Ulrich (2010). "Idea Generation and the Quality of the Best Idea." Management Science 56(4): 591-605.

Goel, V. and P. Pirolli (1992). "The structure of design problem spaces." Cognitive Science 16(3): 395-429.

Goldenberg, O. and J. Wiley (2019). "Individual and Group Brainstorming: Does the Question Matter?" Creativity Research Journal 31(3): 261-271.

Gonçalves, M., C. Cardoso and P. Badke-Schaub (2013). "Inspiration peak: exploring the semantic distance between design problem and textual inspirational stimuli." International Journal of Design Creativity and Innovation 1(4): 215-232.

Gurman Jr, E. B. (1962). The effect of self, task and interaction orientation on brainstorming. PhD, Louisiana State University.

Isaksen, S. G. and J. P. Gaulin (2005). "A Reexamination of Brainstorming Research: Implications for Research and Practice." Gifted Child Quarterly 49(4).

Jablin, F. M. and D. R. Seibold (1978). "Implications for problem - solving groups of empirical research on brainstorming' : A critical review of the literature." Southern Speech Communication Journal 43(4): 327-356.

Kalargiros, E. (2014). The effect of inspirational facilitation on brainstorming effectiveness: A test of Osborn's original ideas. 3582312 Ph.D., New Mexico State University.

Karwowski, M. and J. C. Kaufman (2017). The Creative Self : Effect of Beliefs, Self-Efficacy, Mindset, and Identity. London, Academic Press.

Kocienda, K. (2018). Creative Selection: Inside Apple's design process. London, Macmillan.

Kohn, N. W. and S. M. Smith (2011). "Collaborative fixation: Effects of others' ideas on brainstorming." Applied Cognitive Psychology 25(3): 359-371.

Law, J. (2004). After Method: Mess in Social Science Research. London; New York Routledge.

Levine, K. J., K. B. Heuett and K. M. Reno (2017). "Re - Operationalizing Established Groups in Brainstorming: Validating Osborn's Claims." The Journal of Creative Behavior 51(3): 252-262.

Lewis, A. C., T. L. Sadosky and T. Connolly (1975). "The effectiveness of group brainstorming in engineering problem solving." IEEE Transactions on Engineering Management(3): 119-124. 
Linsey, J. S., E. F. Clauss, T. Kurtoglu, J. T. Murphy, K. L. Wood and A. B. Markman (2011). "An Experimental Study of Group Idea Generation Techniques: Understanding the Roles of Idea Representation and Viewing Methods." Journal of Mechanical Design 133(3).

McCaffrey, T. (2014). Why You Should Stop Brainstorming. Harvard Business Review. Cambridge, Harvard Business Publishing.

Meadow, A., S. J. Parnes and H. Reese (1959). "Influence of brainstorming instructions and problem sequence on a creative problem solving test." Journal of Applied Psychology 43(6): 413.

Mednick, S. (1962). "The associative basis of the creative process." Psychological review 69(3): 220.

Mello, A. L. and J. R. Rentsch (2015). "Cognitive diversity in teams: A multidisciplinary review." Small Group Research 46(6): 623-658.

Moreno, D. P. and M. C. Yang (2014). Creativity in Transactional Design Problems: Non-Intuitive Findings of an Expert Study Using Scamper. DS 77: Proceedings of the DESIGN 2014 13th International Design Conference.

Nijstad, B. A. and W. Stroebe (2006). "How the group affects the mind: A cognitive model of idea generation in groups." Personality and social psychology review 10(3): 186-213.

Osborn, A. F. (1963). Applied imagination; principles and procedures of creative problem-solving. New York, Scribner.

Parnes, S. J. (1961). "Effects of extended effort in creative problem solving." Journal of Educational psychology 52(3): 117.

Parnes, S. J. and A. Meadow (1959). "Effects of "brainstorming" instructions on creative problem solving by trained and untrained subjects." Journal of Educational Psychology 50(4): 171-176.

Paulus, P. B. and M. T. Dzindolet (1993). "Social influence processes in group brainstorming." Journal of Personality and Social Psychology 64(4): 575.

Piffer, D. (2012). "Can creativity be measured? An attempt to clarify the notion of creativity and general directions for future research." Thinking Skills and Creativity 7(3): 258-264.

Scott, G., L. E. Leritz and M. D. Mumford (2004). "The effectiveness of creativity training: A quantitative review." Creativity Research Journal 16 (3 ): 361-388.

Shih, P. C.-P. (2011). Brainstorming Beyond the Laboratory: Idea Generation Practices in Software Development Firms. PhD, University of California, Irvine.

Shroyer, K., T. Lovins, J. Turns, M. E. Cardella and C. J. Atman (2018). "Timescales and ideaspace: An examination of idea generation in design practice." Design Studies 57: 9-36.

Silvia, P. J., B. P. Winterstein, J. T. Willse, C. M. Barona, J. T. Cram, K. I. Hess, J. L. Martinez and C. A. Richard (2008). "Assessing Creativity With Divergent Thinking Tasks: Exploring the Reliability and Validity of New Subjective Scoring Methods." Psychology of Aesthetics, Creativity, and the Arts 2(2): 68-85.

Sosa Medina, R., L. A. Vasconcelos and C. C. Cardoso (2018). Design briefs in creativity studies. International Conference on Design Creativity (ICDC), Bath, Design Society.

Sosa, R. (2019). "Accretion theory of ideation: evaluation regimes for ideation stages." Design Science 5: e23.

Sosa, R. and J. S. Gero (2016). "Multi-dimensional creativity: a computational perspective." International Journal of Design Creativity and Innovation 4(1): 26-50.

Sutton, R., I. and A. Hargadon (1996). "Brainstorming Groups in Context: Effectiveness in a Product Design Firm." Administrative Science Quarterly 41(4): 685-718.

Taylor, D. W., P. C. Berry and C. H. Block (1958). "Does Group Participation When Using Brainstorming Facilitate or Inhibit Creative Thinking?" Administrative Science Quarterly 3(1): 23-47.

Taylor, D. W. and O. W. McNemar (1955). "Problem solving and thinking." Annual review of psychology 6(1): 455-482.

Treffinger, D. J., S. G. Isaksen and K. B. Stead-Dorval (2005). Creative problem solving: An introduction. Waco, Texas, Prufrock Press.

Valsiner, J., A. Gillespie and V. P. Glăveanu (2015). Rethinking Creativity : Contributions From Social and Cultural Psychology. Hove, East Sussex, Routledge.

Vasconcelos, L. A. and N. Crilly (2016). "Inspiration and fixation: Questions, methods, findings, and challenges." Design Studies 42: 1-32.

Weick, K. E. (1989). "Theory construction as disciplined imagination." Academy of management review 14(4): 516-531.

Weisskopf-Joelson, E. and T. S. Eliseo (1961). "An experimental study of the effectiveness of brainstorming." Journal of Applied Psychology 45(1): 45.

Yannou, B. (2013). "Which research in design creativity and innovation? Let us not forget the reality of companies." International Journal of Design Creativity and Innovation 1(2): 72-92. 
Yee, J. (2017). The researcherly designer/the designerly researcher. Practice-based Design Research. L. Vaughan. London, Bloomsbury Publishing: 155. 